\title{
Counseling practice of community pharmacists for diabetes mellitus patients in Addis Ababa, Ethiopia
}

Nigist Tilahun Teka and Assefa Mulu Baye* (i)

\begin{abstract}
Objective: Pharmacists monitor diabetic patients more often than any other healthcare providers. It is important that they have appropriate counseling practice on diabetes mellitus management. The aim of this study is to assess the counseling practice of community pharmacists for diabetes mellitus patients in Addis Ababa, Ethiopia.

Results: Among 300 community pharmacy professionals, $58.3 \%$ were male. Nearly half of the community pharmacy professionals delivered appropriate counselling service on the appropriate time to administer each oral anti-diabetic drug and missed oral dose. Only $15.3 \%$ of the community pharmacy professionals gave proper counselling on the importance of continuous screening for nephropathy, retinopathy, and neuropathy.
\end{abstract}

Keywords: Counselling practice, Community pharmacists, Addis Ababa

\section{Introduction}

Diabetes mellitus (DM) is a metabolic disorders characterized by hyperglycemia and abnormalities in carbohydrate, fat, and protein metabolism. It results from the metabolic defects in insulin secretion, insulin sensitivity, or both [1].

Type 1 DM accounts for $5-10 \%$ of all diabetes cases [2]. Type 2 DM accounts for majority of DM cases. It occurs when an unhealthy lifestyle (excessive calories, inadequate exercise, and obesity) is superimposed upon a susceptible genotype [3].

The role of pharmacist has altered drastically over the past three decades. Traditionally pharmacists were viewed as individuals who dispensed medical products to the community. The clinical pharmacy grew with the concept of clinical pharmacy services. The ultimate goal of pharmaceutical care is to optimize and improve a patient's medical condition and quality of life [4].

Community pharmacists are the healthcare providers most accessible to the public. Their professional activities cover counselling of patients at the time of dispensing of prescription and non-prescription drugs, provision of drug information to health professionals, patients and public, and participation in health-promotion programs including rational use of drugs, alcohol abuse, tobacco use, drug use during pregnancy, poison prevention and treatment and prevention and management of chronic diseases [5].

Community pharmacists are ideally placed to support in the screening, education and referral of individuals at risk of diabetes. Patients with various symptoms contact community pharmacists and, when indicated, pharmacists refer patients to medical practitioners for further management [6]. They are widely accessible, available, in frequent contact with the public and able to access people who are apparently healthy [7].

Researches indicated that most of the community pharmacies professionals lack time, human resources, therapeutic knowledge and confidence that resulted in low level of counseling service $[8,9]$.

\footnotetext{
*Correspondence: mulubaye@gmail.com

Department of Pharmacology and Clinical Pharmacy, College of Health

Sciences, Addis Ababa University, Addis Ababa, Ethiopia
}

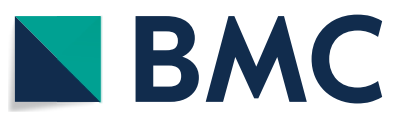

(c) The Author(s) 2018. This article is distributed under the terms of the Creative Commons Attribution 4.0 International License (http://creativecommons.org/licenses/by/4.0/), which permits unrestricted use, distribution, and reproduction in any medium, provided you give appropriate credit to the original author(s) and the source, provide a link to the Creative Commons license, and indicate if changes were made. The Creative Commons Public Domain Dedication waiver (http://creativecommons.org/ publicdomain/zero/1.0/) applies to the data made available in this article, unless otherwise stated. 


\section{Main text \\ Methods \\ Study setting, design and sampling}

The study was conducted at community pharmacies, found in Bole Sub City, Addis Ababa, Ethiopia. The study was conducted from April 2018-June 2018. At the time of the study, there were 122 pharmacies in Bole Sub City. The Sub City has the highest number of community pharmacies and pharmacists in Addis Ababa. An institutional based cross-sectional study design was used.

As the number of pharmacy professionals is limited in the study area, all of the consenting community pharmacists and pharmacy technicians working in the sub city were invited to participate in this survey. The number of community pharmacists practicing in the study area was 310; all the community pharmacists were included in the study. Pharmacy professionals who were the owner of the community pharmacy were excluded to decrease bias associated with misleading and non-genuine information.

\section{Study tools}

Standardized and structured questionnaire was adopted from relevant literature [9] for the purpose of data collection. The questionnaire was self-administered after consent and clear instruction was communicated verbally.

\section{Data analysis}

The cleaned and edited data was entered into SPSS version 23 for analysis. Descriptive statistics with percentage of counseling practice and perceived barriers were identified. Data was presented with tables with frequency and percentage.

\section{Study procedures}

The overall counseling practice was computed from those who counselled always on the following nine diabetes related counseling points [11]. (1) The importance of regular exercise, weight control, and diet. (2) The causes, symptoms and management of hypoglycemia. (3) The appropriate administration, handling, and storage of insulin. (4) The impact of OTC and herbal drugs. (5) Good foot and eye care techniques. (6) Continuous screening for nephropathy, retinopathy, neuropathy. (7) Smoke cessation. (8) The appropriate time to administer each oral anti-diabetic drug and missed oral dose. (9) Matter of stress, tension therefore. All these gave a total score of 9 if a pharmacy professional would counsel on all the above counseling points. Community pharmacy professionals who counselled always on 5 or above of the counseling points were considered with good counseling practice whereas those who counselled always in less than 5 of the above counseling points were considered with poor counseling practice.

\section{Result \\ Socio-demographic characteristics}

Among 310 community pharmacists approached, 300 completed the questionnaire, which gives a response rate of $96 \%$. Among the respondents, 175 (58.3\%) were male. The socio-demographic characteristics of the community pharmacists are shown in Table 1.

\section{Counseling practice}

Counseling on the importance of continuous screening for nephropathy, retinopathy, neuropathy and counseling on good foot care techniques were rarely practiced by $41.3 \%$ and $34.3 \%$ of community pharmacists, respectively. Three-fourth (76\%) of the community pharmacy professionals had 'poor counseling practice' for diabetic patients. Counseling practice of community pharmacists for diabetes patients is indicated in Table 2.

Table 1 Socio-demographic characteristic of the pharmacy professionals in Addis Ababa, 2018

\begin{tabular}{lc}
\hline Characteristics & Frequency (\%) \\
\hline Age (years) & \\
Mean (SD) & $34.23(7.38 \%)$ \\
$<26$ & $27(9 \%)$ \\
$26-36$ & $185(61.7 \%)$ \\
$37-47$ & $71(23.7 \%)$ \\
$>47$ & $17(5.7 \%)$ \\
Gender & \\
Male & $175(58.3 \%)$ \\
Female & $125(41.7 \%)$ \\
Highest pharmacy degree achieved & \\
Diploma & $79(26.3 \%)$ \\
Bachelor's degree & $204(68.0 \%)$ \\
Masters & $17(5.7 \%)$ \\
Work experience in community pharmacy (years) & \\
$<4$ & $88(29.3 \%)$ \\
$4-8$ & $118(39.3 \%)$ \\
$8-12$ & $34(11.3 \%)$ \\
$12-16$ & $44(14.7 \%)$ \\
$<16$ & $16(5.3 \%)$ \\
Monthly income (in USD) & \\
$<127$ & $61(20.3 \%)$ \\
$127-180$ & $80(26.7 \%)$ \\
$>218$ & $82(27.3 \%)$ \\
\hline USD United States of America Dollar; SD, standard deviation & $77(25.7 \%)$ \\
\hline
\end{tabular}

USD, United States of America Dollar; SD, standard deviation 
Table 2 Counseling practice done by community pharmacy professionals for diabetes patients in Addis Ababa, 2018

\begin{tabular}{|c|c|c|c|c|c|}
\hline Counseling topics & Always & Sometimes & Depends on the day & Rarely & Never \\
\hline Importance of regular exercise, weight control, and diet & $81(27 \%)$ & $154(51.3 \%)$ & $15(5 \%)$ & $42(14 \%)$ & $8(2.7 \%)$ \\
\hline Cause, symptoms and treatment of hypoglycemia & $47(15.7 \%)$ & $130(43.3 \%)$ & $20(6.7 \%)$ & $87(29 \%)$ & $16(5.3)$ \\
\hline Appropriate administration, handling, and storage of insulin & $223(74.3 \%)$ & $66(22 \%)$ & $7(2.3 \%)$ & $2(0.7 \%)$ & $2(0.7 \%)$ \\
\hline Impact of OTC and herbal drugs & $84(28 \%)$ & $141(47 \%)$ & $27(9 \%)$ & $42(14 \%)$ & $6(2 \%)$ \\
\hline Good foot care, eye care techniques & $55(18.3 \%)$ & $105(35 \%)$ & $31(10.3 \%)$ & $103(34.3 \%)$ & $6(2 \%)$ \\
\hline $\begin{array}{l}\text { Importance of continuous screening for nephropathy, retinopathy, } \\
\text { neuropathy }\end{array}$ & $46(15.3 \%)$ & $74(24.7 \%)$ & $24(8 \%)$ & $124(41.3 \%)$ & $32(10.7 \%)$ \\
\hline Smoke cessation (when applicable) & $138(46 \%)$ & $104(34.7 \%)$ & $24(8 \%)$ & $20(6.7 \%)$ & $14(4.7 \%)$ \\
\hline $\begin{array}{l}\text { Appropriate time to administer each oral anti-diabetic drug and missed } \\
\text { oral dose }\end{array}$ & $146(48.7 \%)$ & $104(34.7 \%)$ & $26(8.7 \%)$ & $24(8 \%)$ & - \\
\hline Matter of stress, tension, and other illness & 57 (19\%) & $114(38 \%)$ & 60 (20\%) & 67 (22.3\%) & $2(0.7 \%)$ \\
\hline
\end{tabular}

\section{Barriers of counseling services}

'Lack of time' was the most frequently perceived barrier (82\%) followed by 'patients are not interested in preventive activities' with $72 \%$. However, compared to other barriers, 'lack of knowledge or clinical skills' was not a barrier to most of the community pharmacy professionals having the lowest percentage of $31.7 \%$. Perceived barriers of counseling services are indicated in Table 3.

\section{Discussion}

Since DM patients visit pharmacies more frequently for different reasons, this creates an opportunity for community pharmacists to counsel and educate the patient regarding the management and counseling on screening, smoke cessation, weight control and regular exercise, healthy diets and prevention of complications. Current and past smoking are associated with a risk of diabetes mellitus in both men and women [1].

In this research, the most frequently counselled diabetic care service was on the appropriate administration, handling, and storage of insulin (74.3\%) while counseling on weight control, diet and exercise was only $27 \%$ (Table 2).

A research that was done in Katmandu showed that $44 \%$ of the community pharmacy professionals always counseled on the importance of exercise and diet control [9]. These findings are also consistent with a study in Scotland [10]. A research done in Ethiopia also explored that the most frequently counseled diabetics care service were on the importance of exercise diet and weight control (32.5\%) [11].

The optimal delivery of counseling services for diabetic patients on diet, exercise and weight control are very promising as nutrition therapy and physical activity can improve glycemic control in diabetic patients [12-14]. A significant increase in the proportion of patients whose A1c was less than $7 \%$ was observed by the Asheville Project [15].

In the current study, community pharmacists' counseling practice on the importance of continuous screening for nephropathy, retinopathy, neuropath was found to be relatively lower (15.3\%). Similar finding was reported in Qatar [15]. Community pharmacists have the role to encourage diabetic patients' awareness and screening of these complications.

The most frequently perceived barrier was lack of time. This could be due to high burden of customers or shortage of pharmacy personnel, which is also one of the barriers, that is highly frequent in the community pharmacies. Compared to other barriers, 'lack of knowledge or clinical

Table 3 Perceived barriers of counseling for diabetes patients by pharmacy professional in Addis Ababa, 2018

\begin{tabular}{lc}
\hline Barriers & Yes \\
\hline Lack of knowledge or clinical skills & $95(31.7 \%)$ \\
Lack of personnel or resources & $203(67.7 \%)$ \\
Lack of clinical tools & $161(53.7 \%)$ \\
Lack of coordination with other health care professionals & $175(58.3 \%)$ \\
Lack of access to additional training programs & $214(71.3 \%)$ \\
Lack of time & $247(82.3 \%)$ \\
Patients are not interested in preventive activities & $216(72 \%)$ \\
\hline
\end{tabular}


skills' was not a barrier to most of the community pharmacy professionals. The community pharmacists may not able to evaluate their knowledge and clinical skill due to the lower level of the actual counseling practice. Similarly, lack of time was one of the perceived barriers in a study done in Qatar [16]. Increasing the number of pharmacy professionals and establishing private counseling areas in community pharmacies, and promoting the role of pharmacist in diabetes care can help in overcoming these barriers. As indicated by the Asheville project, diabetic patients' clinical and humanistic outcomes could be improved when they are provided with the pharmaceutical care services of community pharmacists, with no concomitant increase in total direct health care costs [15].

\section{Conclusion and recommendation}

According to this study, community pharmacy professionals had demonstrated a lower level of involvement in counseling services for patients with DM. Low interest of patients for preventive activities and lack of time and personnel are the most perceived barriers to a good counseling practice. Provision of advanced on-job training for community pharmacists and enforcing the deployment of more personnel resource is recommended.

\section{Limitations}

The use of a self-administered questionnaire, which depends on honesty and faith of the respondents, could affect the responses as it may be subjected to social desirability bias although it was not clearly observed by this research. As a descriptive cross- sectional study, it was not possible to identify determinant risk factors for poor counseling practice in community pharmacies.

\section{Abbreviations}

DM: diabetes mellitus; ETB: Ethiopian Birr; IRB: Institutional Review Board; OTC: over the counter.

\section{Authors' contributions}

NTT wrote the proposal. AMB and NTT analyzed the data and finalized the write up of the manuscript. Both authors read and approved the final manuscript.

\section{Acknowledgements}

We would like to acknowledge Addis Ababa University School of Pharmacy for technical assistants. We would also like to thank all the community pharmacists in the study sites for their cooperation for the accomplishment of this study.

\section{Competing of interests}

The author declares that they have no competing interests.

\section{Availability of data and materials}

The authors confirm that all data underlying the findings are fully available without restriction. All relevant data is within the manuscript.

\section{Consent for publication}

Not applicable.

\section{Ethics approval and consent to participate}

Verbal consent was obtained from community pharmacists' willingness. Ethical clearance was obtained from the Institutional Review Board (IRB) of School of Pharmacy, College of Health Sciences. The verbal consent was approved by the $\mathrm{IRB}$, as there was no any invasive procedure on the study participants.

\section{Funding}

No funding source.

\section{Publisher's Note}

Springer Nature remains neutral with regard to jurisdictional claims in published maps and institutional affiliations.

Received: 31 August 2018 Accepted: 27 September 2018

Published online: 04 October 2018

References

1. Curtis L. Triplitt, Thomas R, Carlos AA. Diabetes Mellitus. In: Dipiro-pharmacotherapy — a pathophysiologic approach. 9th ed. New York: McGraw-Hill Education; 2014. p. 2546-646.

2. Atkinson MA, Eisenbarth GS, Michels AW. Diabetes mellitus type 1-overview. Lancet. 2014;383(9911):69-82.

3. Powers AC. Diabetes mellitus: diagnosis, classification, and pathophysiology. In: Harrison's Principles of Internal Medicine. 19th ed. United States of America: McGraw-Hill; 2015. p. 2399-407.

4. Palaian S, Chhetri A, Prabhu M, Rajan S, Shankar P. Role of pharmacist in counseling diabetes patients. Int J Pharmacol. 2004;4(1):5.

5. World Health Organization. The role of pharmacist in the healthcare system. 1994.

6. Jaber LA, Halapy H, Fernet M, Tummalapalli S, Diwakaran H. Evaluation of a pharmaceutical care model on diabetes management. Ann Pharmacother. 1996:30:238-43.

7. Berringer R, Shibley MC, Cary CC, Pugh CB, Powers PA, Rafi JA. Outcomes of a community pharmacy-based diabetes monitoring program. J Am Pharm Assoc. 1999;39(6):791-7.

8. Canadian Pharmacist Association. Overcoming barriers to seamless care, a pharmacist's quide to continuous care programs. 2003. http://www.hospi talpharmacyservey.ca/hpc2/Content/SeamlessCareBookFlyer.pdf. Accessed: 21 May 2018.

9. Shrestha M, Maharjan R, Prajapati A, Ghimire A, Shrestha N, Banstola A. Assessment of knowledge and practice of community pharmacy personnel on diabetes mellitus management in Kathmandu district: a cross sectional descriptive study. J Diabetes Metab Disord. 2015;14(1):71.

10. Douglas E, Power A, Hudson S. Pharmaceutical care of the patient with diabetes mellitus: pharmacists' priorities for services and educational needs in Scotland. Int J Pharm Pract. 2007:15:47-52.

11. Erku DA, Belachew SA, Mekuria AB. The role of community pharmacists in patient counseling and health education. Integr Pharm Res Pract. 2017;6:137-43.

12. Association The American Diabetes. Standards of medical care in diabetes. Diabetes Care. 2017:40(suppl 1):S1-132.

13. Andrews RC, Cooper AR, Montgomery AA, Norcross AJ, Peters TJ, Sharp D , et al. Diet or diet plus physical activity versus usual care in patients with newly diagnosed type 2 diabetes: the early ACTID randomized controlled trial. Lancet. 2011;378(9786):129-39.

14. Coppell KJ, Kataoka M, Williams SM, Chisholm AW, Vorgers SM, Mann J. Nutritional intervention in patients with type 2 diabetes who are hyperglycemic despite optimized drug treatment-lifestyle over and above drugs in diabetes (LOADD) study: randomized controlled trial. BMJ. 2010;341:c3337.

15. Cranor CW, Christensen DB. The Asheville Project: short-term outcomes of a community pharmacy diabetes care program. J Am Pharm Assoc. 2003;43(2):149-59. https://doi.org/10.1331/108658003321480696.

16. El Hajj MS, Abu Yousef SE, Basri MA. Diabetes mellitus care in the state of Qatar: a survey of pharmacists' activities, attitudes and knowledge. Int J Clin Pharm. 2018;40(1):84-93. 